\title{
NIETZSCHE E FOUCAULT: SIMILITUDES NO ÂMBITO DO PODER E DO LABOR
}

\author{
NIETZSCHE AND FOUCAULT: SIMILARITIES IN THE \\ FRAMEWORK OF POWER AND JOB
}

\author{
Klayton Santana Porto ${ }^{1}$ \\ Luana Silva Santana ${ }^{2}$ \\ Almir Oliveira Soares Neto ${ }^{3}$
}

Recebido em: 03/2018

Aprovado em: 10/2018

\begin{abstract}
Resumo: O presente texto passa em revista um dado estado da arte, objetivando verificar as proximidades entre o conceito de vontade de potência, criado por Nietzsche, e a concepção de poder, em Foucault. À guisa desse mote, buscamos entabular uma referência para o tema do trabalho enquanto superfície de cruzamento de relações de poder. Tal cruzamento é tomado a partir dos pontos de vista de autores específicos deste tema no viés psicológico e nas concepções de poder, em Nietzsche e Foucault. Assim, declaramos que puderam ser observadas semelhanças no âmbito "produtivo" do poder: pouco controlador, mas incitador de condutas e vontades, opiniões e desejos. Tanto Nietzsche quanto Foucault abordam, de certa forma, o poder como um grande sistema de forças em intensas relações, das quais se originam todos os eventos sociais ou privados.
\end{abstract}

Palavras-chave: Relações de Poder. Multiplicidade, Vontade de potência. Trabalho

\begin{abstract}
The present text reviews a state of the art, aiming to verify the proximity between the concept of power will created by Nietzsche and the conception of power in Foucault. In keeping with this motto, we seek to establish a reference to the theme of work as a cross-over surface of power relations. Such a cross is taken from the points of view of specific authors of this theme in the psychological bias and in the conceptions of power, in Nietzsche and Foucault. Thus, we declare that similarities could be observed in the "productive" realm of power: little controlling, but inciting conducts and wills, opinions and desires. Both Nietzsche and Foucault approach, to a certain extent, power as a great system of forces in intense relations, from which all social or private events originate.
\end{abstract}

Keywords: Power Relations. Multiplicity, Will to Power. Job

\section{Introdução}

\footnotetext{
${ }^{1}$ Doutor e mestre em Ensino, Filosofia e História das Ciências - UFBA Universidade Federal do Recôncavo da Bahia - UFRB Email: klaytonuesb@hotmail.com / klayton@ufrb.edu.br

${ }^{2}$ Doutoranda e mestre em Ensino, Filosofia e História das Ciências - UFBA Faculdade Independente do Nordeste -FAINOR Email: luanas.uesb@ hotmail.com

${ }^{3}$ Mestre em Ensino, Filosofia e História das Ciências - UFBA Faculdade de Tecnologia e Ciências - FTC Email: almir081@hotmail.com
} 
No intuito de delimitar um marco na história das ciências humanas, este trabalho discute um dos principais fundamentos da reflexão de Michel Foucault: a noção de poder. Tal conceito sofreu grandes transformações ao longo de seus escritos, por isso foi eleita, como base de nossa discussão, a sua abordagem como está apresentada na obra Microfísica do Poder, dando relevo às perspectivas de multiplicidade e positividade conferidas por Foucault ao poder.

Pretende-se evidenciar aqui a relação existente entre as noções de Poder em Foucault e o seu correlato em Nietzsche, na medida em que ambos os autores apresentam concepções similares acerca da noção de poder, como se tentará demonstrar ao longo da presente reflexão. Foucault, com a perspectiva rizomática e fluida do poder, sugere que ele seja uma força circulante, não possuída por ninguém, mas que se exerce por todos os lados (FOUCAULT, 2000). Por seu turno, Nietzsche, com seu conceito Vontade de Potência ou Vontade de Poder, caracteriza-o pela sua multiplicidade (LEFRANC, 2005) e por sua atuação incessante na existência dos seres vivos (NIETZSCHE, 2005). Onde residiriam as convergências dessas perspectivas?

A princípio poderia ser feita a seguinte pergunta: por que estudar esse polêmico autor alemão e sua provável influência sobre o não menos debatido psicólogo-filósofo francês? Talvez essa indagação pudesse se nutrir da constatação de que a História, enquanto ciência, pode ser indicada como uma das disciplinas profundamente tangenciadas pela genialidade do francês, porquanto ele consolidou uma nova maneira de fazer história sob seus métodos arqueológicos e genealógicos. E pelo segundo viés, como o indicam os comentadores aqui arrolados, marcado a fundo pela perspectiva nietzschiana.

A própria noção de genealogia é originada, de certa forma, dos escritos de Nietzsche. Como o indica Dallabrida (2002), Foucault se apóia em Nietzsche quando, com seu método genealógico, busca demorar-se, analisar a singularidade dos fatos, encontrar a essência das coisas e aquilo que elas realmente são. Em outras palavras, não é o discurso que é primariamente preferido no estudo, mas o espaço/tempo no qual esse discurso se insere e como é produzido. Foucault (2000) cita Nietzsche para reforçar a questão da genealogia, a qual deve:

Construir seus "monumentos ciclópicos" não a golpes de "grandes erros benfazejos" mas de "pequenas verdades inaparentes estabelecidas por um método severo". (...) A genealogia não se opõe à história como a visão altiva e profunda do filósofo ao olhar de toupeira do cientista; (...). Ela se opõe à pesquisa da "origem" (FOULCALT, 2000, p. 23). 
Ou seja, o que se busca, através do método genealógico, especificamente na introdução de Microfísica do Poder (2000), segundo Machado, é encontrar as explicações para as condições de possibilidade de surgimento de algo, a exemplo de um saber; sendo que estas condições os situam como "elementos de um dispositivo de natureza essencialmente estratégica” (FOULCALT, 2000, p. 10). Segundo Machado, o que está em jogo é a análise do porquê dos saberes que tenta explicar a existência destes e suas transformações enquanto peças de relações de poder ou dispositivos políticos, "que em uma terminologia nietzschiana [Foucault] chamará genealogia" (FOULCALT, 2000, p. 10). Quer dizer, para os autores indicados, Foucault é atravessado pelo nietzschianismo dorsalmente, a saber, em sua perspectivação metodológica.

Segundo Dreyfus e Rabinow (1995), a leitura de Nietzsche foi o meio através do qual Foucault se voltou novamente para os perigos da abordagem interpretativa. O método genealógico de Nietzsche deu a Foucault, através da percepção de como o poder faz uso da ilusão do sentido para se favorecer, bons motivos para ser crítico em relação ao método hermenêutico. Razão? Ao invés de supor uma verdade constituída de uma vez por todas, a ser meramente resgatada pelo exercício hermenêutico, o que a genealogia permite é um recuo: indagar sobre o modo de constituição de um discurso, suas condições reais dadas por um determinado cenário histórico.

Foucault, leitor de Nietzsche, por mais que contraponha ou desenvolva algumas idéias de forma diferenciada, tem a sua rede conceitual contaminada por aquela elaborada pelo alemão (DREYFUS; RABINOW, 1995).

Embora seja um caminho razoável traçar a influência de Nietzsche em Foucault, o presente trabalho não possui esse escopo. Antes, o que se deseja é demarcar certos traços sobre suas concepções de poder, à guisa do que emerge essa influência. O foco, portanto, é a constituição da noção de poder. Dele deriva o corolário de uma presença insidiosa.

O alemão do século XIX construiu uma filosofia "destruidora" de valores e verdades. Sua empreitada, em denunciar as idéias por trás de cada enunciado disseminado como verdade, o impulsionou a desenvolver uma rede epistemológica muito apurada e inovadora.

Em sua guerra contra a moral e a valoração decorrente dela, Nietzsche arma-se de conceitos poderosos. Em meio a essa rede encontra-se o conceito de "Vontade de Potência". Esse conceito está intimamente ligado ao tema dos valores, porquanto nenhum povo seria capaz de sobreviver caso não fosse apto a avaliar, a seu modo, o que é o bem e o mal (MACHADO, 2001). Em outras palavras, a vontade de poder incita, ou melhor, embasa a vontade da verdade, 
que é inerente aos seres humanos. O termo "verdade" e sua respectiva semântica presente na argumentação de Nietzsche estão profundamente imbricados na questão do poder. De fato, Foucault captura esse ponto específico no discurso de Nietzsche e tece um diálogo com o alemão, circunscrito na Microfísica do Poder $^{4}$ (2000):

O importante, creio, é que a verdade não existe fora do poder ou sem poder (não é - não obstante um mito, de que seria necessário esclarecer a história e as funções - a recompensa dos espíritos livres, o filho das longas solidões, o privilégio daqueles que souberam se libertar). A verdade é deste mundo; ela é produzida nele graças a múltiplas coerções e nele produz efeitos regulamentados de poder. Cada sociedade tem seu regime de verdade, sua "política geral" de verdade: isto é, os tipos de discurso que ela acolhe e faz funcionar como verdadeiros; os mecanismos e as instâncias que permitem distinguir os enunciados verdadeiros dos falsos, a maneira como se sanciona uns e outros; as técnicas e os procedimentos que são valorizados para a obtenção de verdade; o estatuto daqueles que têm o encargo de dizer o que funciona como verdadeiro (FOULCALT, 2000, p.12).

Foucault (2000) defende aqui a idéia de que a verdade é um produto do poder, e sendo este poder algo deste mundo, o mundo das relações humanas, a verdade está circunscrita nas múltiplas coerções existentes aí. Ela está aprisionada nesse mundo, ou melhor, em cada “divisão" desse mundo: em outras palavras, em cada sociedade. Exatamente porque cada sociedade adota seus mecanismos particulares de reconhecimento de enunciados verdadeiros ou falsos.

A coleção "Ditos \& Escritos" traz, na apresentação do volume dois, referências à inspiração e leitura da obra de Nietzsche. Strathern (2003) afirma que Foucault se sente "livre" para criar após ler Nietzsche: "a ênfase de Nietzsche no papel central do poder em toda atividade humana caiu sobre Foucault como um raio" (STRATHERN, 2003, p. 22).

\section{Foucault e o poder}

O poder deve ser analisado como algo que circula, ou melhor, como algo que só funciona em cadeia. Nunca está localizado aqui ou ali, nunca está nas mãos de alguns, nunca é apropriado como uma riqueza ou um bem. O poder funciona e se exerce em rede. Nas suas malhas os indivíduos não só circulam mas estão sempre em posição de exercer este poder e de sofrer sua ação; nunca são o alvo inerte ou consentido do poder, são sempre centros de transmissão. Em outros termos, poder não se aplica aos indivíduos, passa por eles." (FOUCAULT, 2000, p. 183).

\footnotetext{
${ }^{4}$ FOUCAULT, M. Microfísica do Poder. Ed. 15. Rio de Janeiro: Graal, 2000.
} 
É importante frisar um aspecto fundamental do poder em Foucault, de modo a esclarecer o que foi explicitado anteriormente. De acordo com Roberto Machado, não existe uma teoria geral do poder para Foucault. Segundo ele, o autor acredita que não há algo unitário e global denominado poder, não há uma essência a ser buscada. O que existe é uma prática social construída historicamente; em outras palavras, "o poder é uma correlação de forças e relações" (DALLABRIDA, 2002, p.27). Portanto, se "Foucault reconhecia que o mais importante aspecto do poder estava nas relações sociais" (STRATHERN, 2003, p. 52), é nesse âmbito social que se tentará aqui capturar o que Foucault nomeia como poder.

As verdades são os componentes essenciais dos saberes. Estes últimos são dispositivos de controle empregados pelo poder. À guisa da perseguição semântica do poder na letra foucaultina, encontramos uma espécie de teia conceitual que se reforça mutuamente: poder, verdade, saber. É importante ressaltar que, para Foucault (2000), a "verdade" não é um conjunto de coisas verdadeiras a descobrir ou a aceitar, mas um conjunto de regras que distinguem o verdadeiro do falso e que atribuem efeitos de poder ao verdadeiro. As ciências sexuais (FOUCAULT, 1999) ilustram de maneira pertinente este argumento que des-substancializa a verdade, visto que, segundo Foucault (2000), uma das características da verdade é que ela "é centrada na forma do discurso científico e nas instituições que a produzem" (FOUCAULT, 1999, p. 12).

Na História da Sexualidade, A Vontade de Saber, essas ciências são apresentadas como fatores pregnados no controle mais eficiente dos corpos a partir de sua sexualidade, uma das grandes forças motivadoras do homem. Strathern (2003, p. 68) corrobora, ainda, com a idéia: "[Na História da Sexualidade] A medicina e a psicologia começaram, na época, a exercer poder sobre o corpo, e, com isso, a sexualidade passou a ser submetida ao controle social". Observase, neste caso, dois exemplos destes dispositivos de controle no ambiente da saúde: a psicologia e a medicina. Dois saberes contituindo a materialidade, a verdade de algo que vivifica o corpo do homem. O manejo da sexualidade humana, portanto, se faz mediante as metas estabelecidas por esses dois saberes.

E como entra o terceiro elemento da rede conceitual nesse jogo? O poder fornece subsídios ao surgimento das verdades e dos saberes. Tal afirmação se fundamenta em outra característica da verdade apontada por Foucault (2000): “[a verdade] está submetida a uma constante incitação econômica e política (necessidade de verdade tanto para a produção econômica, quanto para o poder político)" (FOUCAULT, 2000, p.12-13); subsidia, também, 
inclusive, a origem de focos de transmissão de "contra-poderes" ou poderes periféricos, os quais estariam emergindo destas incitações políticas e econômicas. O que é corroborado pela perspectiva de Lebrun, ao afirmar que "O poder é menos o controlador de forças que seu produtor e organizador" (FOUCAULT, 1999, p.19). Em outras palavras, da inter-relação de todas as instâncias sociais e da intersecção das relações de forças, como afirmara Dallabrida (2002), emergem os discursos e movimentos representantes de outras instâncias de transmissão do poder, que não se caracterizam como um foco central.

Essa não centralização do poder seria o primeiro pilar de sustentação do conceito de poder adotado pelo autor. Um segundo pilar reside na desconstrução da imagem do poder como algo somente repressor.

Moraes e Nascimento (2002) afirmam que o poder para Foucault é muito mais produtivo do que repressivo, cria realidades, sujeições e objetos. Ou seja, mesmo que pela intervenção aparentemente restrita de uma proibição, imperiosa e repressora, o principal resultado da atuação do poder de um indivíduo sobre o outro é a interferência no comportamento deste outro. Aquele que em determinado momento encontra-se ao lado do poder que está sendo exercido, almeja manipular a ação, o pensamento, a opinião e as escolhas daquele que sofre a atuação deste seu suposto poder, em vista de seus próprios interesses. Corroboram para isso os saberes, visto que estes obedecem, antes de tudo, àquele que o "patrocina", o poder. Quanto a isso, Strathern afirma: "o poder estava também envolvido na produção e uso do saber" (STRATHERN, 2003, p.52). Foucault se remete a este aspecto muito claramente:

(...) se o poder só tivesse a função de reprimir, se agisse apenas por meio da censura, da exclusão, do impedimento, do recalcamento, à maneira de um grande superego, se apenas exercesse um modo negativo, ele seria muito frágil. Se ele é forte, é porque produz efeitos positivos a nível do desejo como se começa a conhecer - e também a nível do saber (FOULCALT, 2000, p. 148).

Nessa perspectiva, conceber poder unicamente como força repressiva seria torná-lo ineficaz, frágil; dificilmente o poder seria capaz de cumprir o papel controlador dos movimentos que se sucedem em uma cadeia de conexões. O que é reiterado na citação de Foucault ao enunciar com clareza que o poder unicamente repressor não seria capaz de atingir de forma eficaz os indivíduos. Essa afecção se consegue somente através dos desejos e do prazer, espécie de excitação que o exercício do poder é capaz de provocar em quem está implicado em suas malhas. Ou como Lebrun (1999) coloca, a força raramente é representada pela violência, mas, muitas vezes, simplesmente pelo charme da pessoa amada quando "extorque" (positivamente) 
alguma decisão: uma relação amorosa é, antes de tudo, uma relação de forças. Em outras palavras, o poder, genericamente antes de ser repressor, é sobretudo um produtor. Ele produz opiniões, discursos, comportamentos. A eficácia está presente quando se coloca o poder sob essa perspectiva: produz efeitos no âmbito do desejo dos sujeitos, gerando neles a sensação de prazer. Então, de certa forma, o comportar-se de acordo com o poder incita prazer e, portanto, maior adesão de sujeitos controlados.

Por que falar de sexualidade ao se discutir poder? A referência à relação amorosa como relação de forças pode até ser válido, mas até que ponto a sexualidade, que é algo tão circunscrito no indivíduo, pode interferir nas relações de forças em âmbitos mais gerais? De que forma ela se relaciona com o poder e o saber e deles recebe interferência? Que implicações teria esse jogo discursivo sobre a sexualidade?

Se o sexo é reprimido, isto é, fadado à proibição, à inexistência e ao mutismo, o simples fato de falar dele e de sua repressão possui como que um ar de transgressão deliberada. Quem emprega essa linguagem coloca-se, até certo ponto, fora do alcance do poder; desordena a lei; antecipa, por menos que seja, a liberdade futura (FOULCALT, 1999, p. 12).

Sendo assim, o simples fato de se discutir a sexualidade neste texto o conferiria "um ar de transgressão deliberada" e, a partir desta verbalização, seria possível "antecipar a liberdade"... Mas de que forma? - pergunta-se. Foucault, ainda no primeiro capítulo de Vontade de Saber, nos ilumina com supostas respostas a esta tendenciosa pergunta. Ele afirma que há muitos anos só se fala de sexo fazendo pose, justamente porque parece haver a consciência de que se está desafiando a ordem estabelecida, parece haver algo como uma revolta (FOUCAULT, 1999):

a vontade de mudar a lei e o esperado jardim das delícias - eis o que, sem dúvida, sustenta em nós a obstinação em falar do sexo em termos de repressão; eis, também, o que explica, talvez, o valor mercantil que se atribui não somente a tudo o que dela se diz como, também, ao simples fato de dar atenção àqueles que querem suprimir seus efeitos. Afinal de contas, somos a única civilização em que certos prepostos recebem retribuição para escutar cada qual fazer confidência sobre seu sexo: como se o desejo de falar e o interesse que disso se espera tivessem ultrapassado amplamente as possibilidades da escuta, alguns chegam até a colocar suas orelhas em locação (FOULCALT, 1999, p. $12,3)$.

Foucault (1999) complementa ainda que: 
Ora, uma primeira abordagem feita deste ponto de vista parece indicar que, a partir do fim do século XVI, a "colocação do sexo em discurso", em vez de sofrer um processo de restrição, foi, ao contrário, submetida a um mecanismo de crescente incitação; que as técnicas de poder exercidas sobre o sexo não obedeceram a um princípio de seleção rigorosa, mas, ao contrário, de disseminação e implantação das sexualidades polimorfas e que a vontade de saber não se detém diante de um tabu irrevogável, mas se obstinou - sem dúvida através de muitos erros - em constituir uma ciência da sexualidade (FOULCALT, 1999, p. 17, 8).

A citação se encaminha na direção do tratamento a ser conferido aos problemas colocados até aqui. Um primeiro ponto a ser levantado sobre a relação da sexualidade com o poder é o sentimento de "transgressão deliberada", que confere ao indivíduo um status de poder. Segundo Foucault (2000), apenas a fabricação do enunciado já pode ser considerada índice de luta de poder. Quando se fala de "valor mercantill", "colocação do sexo em discurso" e "orelhas em locação", evidencia-se a questão econômica imbricada nesta problemática. Há, no sistema capitalista, algo mais significativo nas relações de força que o próprio capital? A questão imbrica transação econômica com a sexualidade.

Giddens (1993), apesar de ter uma concepção de sexualidade diferenciada da de Foucault, não deixa de inseri-la, também, nos campos do poder. Em sua leitura de Foucault, afirma que "Civilização significa disciplina, e disciplina, por sua vez, implica controle dos impulsos interiores, controle este que, para ser eficaz, tem de ser interno" (GIDDENS, 1993, p. 27). Desta forma, o poder exercido mediante o saber erigido pelas Ciências Sexuais "produziria 'corpos dóceis', controlados e regulados em suas atividades, em vez de espontaneamente capazes de atuar sobre os impulsos do desejo" (GIDDENS, 1993, p. 27). A respeito das ciências sexuais, Giddens coloca em relevo o que Foucault destaca, a saber, que "apenas a sociedade ocidental moderna desenvolveu uma ciência da sexualidade" (GIDDENS, 1993, p. 29), a qual teria derivado do princípio da confissão com o conhecimento acumulado sobre o sexo, tornando-o o ponto principal do confessionário moderno.

Por fim, tem-se que, de forma sutil, invisível e eficaz, o poder controla os indivíduos que se sentem "livres" e dotados de poder ao transgredir a aparente repressão imposta por um suposto poder central. Suposto porque o que ocorre é que, nas relações de força, ou seja, na rede de relações na qual se reflete o poder, os indivíduos são capturados, principalmente no nível do desejo, e domesticados ou docilizados de acordo com a tendência de exercício do poder no momento em que se põe em ação. Os sujeitos são capturados pela sua vontade própria e por fim adestrados ao seu interesse, nesse caso capitalista, de produção e perpetuação do sistema.

Como entender essa dinâmica de uma associação voluntária do sujeito a uma rede de 
exercício de poder que ele próprio cauciona e fortalece em sua adesão? Não se trata de uma mera servidão voluntária, porque, ao menos na letra de Foucault, o próprio sujeito se constitui, expande suas possibilidades vitais, atualiza suas potências na reciprocidade do jogo de poder no qual está inserido. Cremos que esse problema se compreende, sem a necessidade de lançar mão do marxismo, a partir das conexões possíveis a serem explicitadas por um certo uso que Foucault faz de Niestzsche.

\section{Nietzsche e a Vontade de Potência ou Vontade de Poder ${ }^{5}$}

Onde quer que encontrasse o que é vivo, encontrei a vontade de poder. Até na vontade daquele que obedece encontrei a vontade de ser senhor. (NIETZSCHE, 2005, p. 107)

Alguns comentadores indicam que o conceito vontade de poder é o elemento mais importante na obra de Nietzsche (LEFRANC, 2005; STRATHERN, 1997). A abordagem traçada a este termo, a saber, o "poder”, por Nietzsche, é diferenciada, de modo geral, daquela de Schopenhauer. O tratamento dado por este último está relacionado ao âmbito essencialmente metafísico do $e u$, enquanto que o de Nietzsche flutua diante de aspectos mais naturais, que indicam com mais contundência os elementos concretos da condição humana (LEFRANC, 2005; MACHADO, 2001). Devido à sutil discrepância percebida na argumentação de autores estudiosos de Nietzsche, buscaremos dispô-las separadamente, de modo a abranger os significados que, em muitos aspectos, são convergentes, para, em seguida, interpelar o autor na abordagem do seu conceito.

Lefranc (2005) afirma que, para Nietzsche, toda vontade é sempre uma vontade de poder, que é a determinação da qual depende toda e qualquer forma individual de querer. Segundo ele, Nietzsche permanece na área de uma psicologia e de uma antropologia que sugerem como "natural" que todos os seres vivos busquem a felicidade. E sendo o homem um ser vivo entre os seres vivos não pode ser excluído desta lógica. A vontade de poder não é uma paixão entre outras, mas só ela pode explicar toda e qualquer outra paixão, desejo e vontade, as quais são, por fim, uma manifestação do que lhe é originário. Dessa forma, Lefranc (2005) afirma que a vontade de poder pode ser entendida como o elemento que comanda toda reflexão

\footnotetext{
5 A questão da diferença definida por Lebrun (1999) entre "poder" e "potência" não será levada em conta aqui, visto que autores conceituados, ao escreverem sobre este conceito de Nietzsche, ora citam "poder" ora "potência" sem distinção explícita entre eles. Portanto, os dois termos serão aqui tratados como tendo o mesmo significado em Nietzsche.
} 
da psicologia, que, segundo ele, se torna "teoria da vontade de poder" (LEFRANC, 2005, p.114).

Alguns outros aspectos importantes e que são ressaltados por Lefranc (2005) acerca do conceito em voga devem ser alocados aqui. O primeiro se remete à evolução do homem, no sentido de que houve um "movimento" progressivo da vontade de poder a partir das forças naturais, incrementadas pela técnica e pela tecnociência e, sobretudo, pelo domínio interno dos instintos e dos desejos. Segundo Lefranc (2005), Nietzsche teria expressado isto ao analisar a hipótese da floresta primitiva habitada pelos selvagens que, gradualmente, teriam desenvolvido formas de dominar o mundo externo, a natureza e o universo interno dos desejos e instintos. $\mathrm{O}$ segundo aspecto refere-se ao termo vontade de poder, enquanto enunciado no singular. De acordo com Lefranc (2005), falando-se deste modo, no singular, como de um organismo ou de um povo, qualifica-se sua realidade como constituída por um "jogo complexo e cada vez particular de forças que agem e reagem sem cessar" (LEFRANC, 2005, p. 116). Este jogo complexo ressalta, então, para ele, que a definiçãa mais próxima da realidade do conceito de vontade de poder é a multiplicidade.

Lefranc (2005) ainda apresenta outras idéias para a compreensão deste conceito de Nietzsche. Afirma, por exemplo, que a noção de vontade de poder está muito além do domínio da vida humana moral e social, já que este domínio faz parte dessa noção, mas não a define. Ele justifica essa afirmativa ao colocar que o "mundo inteiro, de um extremo a outro, é vontade de poder" (LEFRANC, 2005, p. 123). Esta citação sem dúvida reafirma a idéia da multiplicidade apontada anteriormente, dando, ainda, uma espécie de horizonte cosmológico a uma certa interpretação reducionista de uma vontade centrada com exclusividade no homem. A vontade de poder, portanto, na perspectiva do autor, ganharia contornos bem mais amplos que um movimento volitivo do homem para se afirmar. Todo o cosmo é atravessado por essa vontade. O homem, em lhe constituindo, também participaria dessa dinâmica.

Um aspecto sutil do conceito de vontade de poder é a sua relação com a vida, no sentido semântico do termo, ou seja, de seu significado. Este conceito é usualmente tomado, segundo Lefranc (2005), como princípio fundamental do viver. No entanto, este autor defende a idéia de que Nietzsche não concebeu dessa forma a relação entre viver e vontade de poder. A vontade de poder está além da questão da vida, pois esta se encontra presente em um certo nível de complexidade da vontade, "quando não há mais apenas equilíbrio, organizações de forças sempre diferentes, mas organismos, formas de seres vivos individualizados" (LEFRANC, 2005, p. 126). Ou seja, considerando a definição da vontade de poder como multiplicidade de 
forças no mundo, e este mundo possuindo seus aspectos inorgânico e orgânico, a vida não estará de forma alguma representando todas as forças implicadas na sua sustentação. Mas a vontade de poder, sim, abarcaria a vida e os demais âmbitos relevantes no "jogo complexo e cada vez particular de forças que agem e reagem sem cessar" (LEFRANC, 2005, p. 116).

Para pontuar a argumentação encetada por Lefranc (2005), consideremos:

(...) é o mesmo mundo que o mecanismo científico pretende explicar e que a vontade de poder permite interpretar em todos os níveis. Desde que se torna interpretação, a inteligibilidade não exige mais a posição de nenhum trásmundo, mas ela é o deciframento da única realidade imediatamente dada, a dos desejos e das paixões, estendida ao corpo da experiência interna e enfim ao próprio mundo em sua totalidade, "visto" de alguma forma do interior. (LEFRANC, 2005, p.127).

Esta citação contém, de forma evidente, o que se pode afirmar como um dos aspectos da "psicologia de Nietzsche". Exatamente porque a noção de vontade de poder, enquanto impulsionadora da multiplicidade de formas de apreender, de dominar o mundo, possibilita compreender a individualidade, ou o corpo da experiência interna de forma precisa: partindo dos desejos e das paixões, bases importantes da perspectiva, ou do ponto de vista individual, torna-se o mundo inteligível dentro das interpretações que incessantemente decifram o mundo em sua totalidade. Isto se remete ao chamado perspectivismo do autor. Em outras palavras, como afirma Dallabrida (2002), a verdade, nesse âmbito, depende da perspectiva escolhida, ou seja, não há verdade absoluta, um significado fundamental que desvele a realidade completamente. "Logo, toda leitura é eminentemente axiológica, resultante de uma perspectiva ética e histórica, orientada pelos valores e pelo contexto histórico-social de quem interpreta" (DALLABRIDA, 2002, p. 30). Este argumento demonstra, de certa forma, o alcance do conceito de vontade de poder, que abrange os movimentos humanos individual e coletivamente, além de delimitar as influências não-humanas no comportamento humano.

Por sua vez, Machado (2001) faz uma leitura do livro Assim Falava Zaratustra, colocando em relevo o conceito vontade de potência. $\mathrm{O}$ autor trata do conceito de um modo muito próximo ao tratamento dispensado pelo comentador analisado anteriormente. Ele enfatiza veementemente à questão do super-homem outro conceito relativo ao homem superior ou àquele que expressa abundantemente sua vontade de potência, o qual representa o bem da humanidade que deve ser criado. Retomando a idéia de que o mundo do valor é afirmado pela vontade de poder. Segundo ele, para Nietzsche "nenhum povo poderia viver se não avaliasse de modo próprio, o que é o bem e o mal por sua vontade de potência" (MACHADO, 2001, p. 
73). Tem-se, assim, a vontade de potência como princípio de toda judicação que o sujeito é competente para realizar (MACHADO, 2001). Considerando-se que para Nietzsche o homem é aquele que avalia (NIETZSCHE, 2005), é possível corroborar a afirmação de Machado (2001) de que o fundamento dos valores se encontra na própria condição humana de existência e não reside em um universo metafísico.

Machado (2001) ainda mostra como a vida, segundo Nietzsche, deve ser aquilo que se apresenta como vontade afirmativa de potência, através de uma auto-superação do além do bem e do mal: “(...) vida como vontade de potência no sentido de auto-superação: tendência a subir, vitória sobre si mesma, domínio de si mesma, esforço sempre por mais potência” (MACHADO, 2001, p. 101). Isso permite compreender a dinâmica mutável da vida, como Nietzsche a apresenta em "Do canto de dança": "versátil e obstinada" (NIETZSCHE, 2005, p. 102). Machado (2001) anuncia, então, que, segundo Zaratustra, não existem valores imperecíveis, pois estes são exercícios da vontade de potência que, em seu exercício, requer a destruição de valores, a fim de possibilitar a criação de novos.

Até aqui, tentou-se alguns sentidos possíveis para a expressão da vontade de potência. Tentou-se evidenciar que cada um teve sua maneira particular de dominar, de tornar inteligível o conceito. A vontade de potência possui por trás a vontade de verdade que leva o sujeito a "tornar pensável todo o existente (...) de submeter, dobrar o mundo à vontade de potência" (MACHADO, 2001, p. 100). A esse propósito, diz Nietzsche:

Chamais "vontade de verdade", sábios insignes, o que vos impele e vos excita? Vontade de tornar concebível tudo o que existe, assim chamo, eu, vossa vontade (...) Mas tudo o que existe deve também se adaptar e se curvar! Assim o quer vossa vontade. Que tudo o que existe se humilhe e se submeta ao espírito como seu espelho e sua imagem. (...) É essa toda a vossa vontade, sábios insignes, uma vontade de poder e mesmo quando falais do bem e do mal e das apreciações de valores (NIETZSCHE, 2005, p. 106).

É possível sugerir, a partir destas colocações, que a verdade absoluta inexiste para Nietzsche. Sendo assim, privilegia-se ainda mais a necessidade de explicitar seu conceito a partir de suas próprias palavras.

Nietzsche (2004) declara que sua tese é que há possibilidade de explicar a vida instintiva como elaboração e ramificação da vontade de poder. Todo o desprezo do ocidente pelos instintos derivaria do próprio sufocamento dessa realidade inerente ao mundo. $\mathrm{O}$ ocidente desenvolveu uma espécie de horror aos instintos, atribuindo-lhes características degrandantes ao homem. Ao contrário, Nietzsche pensa que caso reconduzisse todas as funções orgânicas à 
vontade de poder se encontraria nela a solução para:

o problema da geração e nutrição (...) então se obteria o direito de definir toda força atuante, inequivocamente, como vontade de poder. O mundo visto de dentro, o mundo definido e designado conforme o seu "caráter inteligível" seria justamente "vontade de poder" e nada mais (NIETZSCHE, 2004, p. 66).

Ao se referir aos filósofos, Nietzsche (2004) afirma que estes devem constatar e formular os conjuntos de valorizações, criações de valores de outrora que se tornaram, temporariamente, "verdades". Segundo Nietzsche (2004), os filósofos devem tornar visíveis, concebíveis, manuseáveis, apreensíveis todos os fatos e valorizações, abreviando até o tempo, a fim de "dominar" todo o passado. Os filósofos verdadeiros, enfim, deverão comandar e legislar os homens, e, para isso, segundo Nietzsche (2004), disporão do trabalho prévio de todos os filósofos, de todos os dominadores do passado, já que eles são os que agarram o futuro através de um conhecer, que é criação e legislação (NIETZSCHE, 2004).

Poder-se-ia compreender todo e qualquer dogmatismo como uma vontade de poder se expressando na vontade de verdade? Estariam as filosofias dotadas desse movimento? Também as ciências? Esse movimento seria inerente a todos os saberes? As palavras do autor encaminham na direção da reflexão:

Este mundo: uma imensidade de força sem começo e sem fim (...) que não se torna maior nem menor, que não consome, mas se transforma, um todo de uma grandeza invariável, uma economia sem dispêndio nem perda, mas sem ganho nem acréscimo, cercado do "nada" como limite, sem nada que se dissipe ou desapareça, sem nada de infinitamente extenso; força determinada encerrada num espaço determinado, e não num espaço que estaria de alguma forma "vazio", mas força que é em toda parte um jogo de forças e de ondas de forças ao mesmo tempo unas e múltiplas, acumulando-se aqui, diminuindo lá, um oceano de forças desencadeadas contra elas mesmas e flutuantes, eternamente em mudança, eternamente em recuo, com longos anos de retorno, (...), voltando depois da profusão à simplicidade, do jogo dos contrastes ao desejo de harmonia, afirmando-se ainda nesta identidade dos percursos e dos anos, consagrando-se ele mesmo como o que deve retornar eternamente, como um devir que não conhece saciedade, nem desgosto, nem lassidão [...] Este mundo é o mundo da vontade de poder e nada mais. (NIETZSCHE apud LEFRANC, 2005, p. 126, 7)

\section{O poder/potência no fenômeno do trabalho humano}

Analisa-se aqui o fenômeno do trabalho em dois aspectos: um referente às possibilidades que são conferidas ao sujeito que trabalha, de agente que atua transformando a 
natureza, bem como a outros sujeitos e ainda a si próprio. Um outro aspecto está relacionado às condições de trabalho, sendo que nelas estão inseridas, além do próprio ambiente físico, disponibilizado aos trabalhadores, as relações entre eles e seus patrões, bem como as relações horizontais entre os próprios trabalhadores. Para tal, será apresentado um breve apanhado histórico, apoiado na reflexão psicológica apresentada por Dejours, bem como no trabalho de análise de alguns comentadores da psicologia do trabalho, para, enfim, retornarmos a Foucault e Nietzsche, inserindo o problema na perspectiva da vontade de potência. Dejours (1992) constrói sua argumentação em torno da história do movimento operário desde a Revolução Industrial, no final do século XIX.

Após a Segunda Guerra e até 1968, o movimento operário continuou em busca de melhorias nas condições de trabalho. Entretanto, apenas os movimentos mais poderosos, situados em grandes empresas onde o trabalho tinha um valor econômico estratégico, conseguiram rápidas melhorias na relação saúde-trabalho (DEJOURS, 1992). Coincidência ou não, as grandes corporativas melhoraram suas condições de trabalho e ampliaram seus lucros por serem centros importantes da economia. $\mathrm{E}$ as empresas mais isoladas, instaladas em regiões pouco industrializadas, viveram o processo oposto: movimentos operários fracos e malsucedidos em suas reivindicações.

A entrada da medicina do trabalho nas fábricas e empresas, após a Guerra, marcou de forma mais forte, nesse momento, a utilização do saber em função de estratégias de obtenção de lucro. Observa-se isto na afirmativa do próprio Dejours (1992, p. 20):

Certos empregadores contratam um médico, a título individual, para fazer seleção na contratação, e para se protegerem de certos riscos que, a partir de então, estão ligados a penalidades financeiras (indenizações, etc) (DEJOURS, 1992, p. 20).

Nesse momento é perceptível a presença das ciências da saúde no mundo da economia, da produção, enquanto formas de gestão que buscam o lucro.

Dejours (1992) denomina de revelação do corpo o segundo período da "história da saúde dos trabalhadores". Sua reflexão distancia-se das questões relativas à sobrevivência propriamente dita e aproxima-se de um modo de pensar que toma como ponto de partida o corpo, sob o que subjaz algo mais sensível à eficácia do poder. A ênfase do seu texto mostra como a luta pela sobrevivência fornece lugar à luta pela saúde do sujeito, argumentando que a idéia de corpo, como alvo primário da exploração, deve ser revisada porque, ao se inverter essa proposição, chegar-se-ia a algo como: 
Tudo se daria como se as condições de trabalho nocivas só atingissem o corpo após tê-lo submetido, domesticado e adestrado como a um cavalo de tração. Docilidade que (...) depende de uma estratégia concernente ao aparelho mental, para dele anular as resistências que ele opõe, espontaneamente, à exploração (DEJOURS, 1992, p. 21).

Em outras palavras, o corpo seria um alvo secundário, pois o alvo é o aparelho mental que teria de ser primariamente adestrado, de modo que o corpo apenas obedecesse a este. Essa primazia da alma, como alvo do poder moderno, também é salientada por Foucault (1999, p. 18) quando explicita as formas modernas de controle do sujeito: “(...) não é mais o corpo, é a alma. À expiação que tripudia sobre o corpo deve suceder um castigo que atue, profundamente, sobre o coração, o intelecto, a vontade, as disposições".

O último período a que se remete Dejours (1992), a fim de debater esse tema, diz respeito ao surgimento de uma nova problemática na questão da saúde no trabalho, a saber, a saúde mental. Apresenta três razões da ocorrência desse fato: a primeira diz respeito à economia. O sistema produtivo pensado por Taylor se esgota, pois "as greves, as paralisações de produção, as operações padrão, o desperdício, o absenteísmo, a rotatividade, a sabotagem da produção e a 'alergia ao trabalho' levam a procurar soluções alternativas” (1992, p. 23); a segunda encontra-se no âmbito do controle social, ao afirmar que esse sistema organizacional de uma produtividade ultracontrolada não garante a sua superioridade; a terceira e última razão diz respeito ao terreno ideológico: "o sistema Taylor é denunciado como desumanizante e acusado de todos os vícios, principalmente pelos operários e também por uma parte do patronato" (DEJOURS, 1992, p. 23). Trata-se de um sistema de controle em vias de falência?

Taylor constrói um sistema baseado em uma "nova tecnologia de submissão, de disciplina do corpo, especialmente as exigências de tempo e ritmo de trabalho" (DEJOURS, 1992, p.19). O que esta tecnologia efetuou foi, de fato, a separação do trabalho manual do intelectual, neutralizando a atividade mental dos operários. O resultado de uma tal operação é um corpo dócil e disciplinado entregue, sem resistência, às injunções da organização do trabalho, ao engenheiro de produção e à direção hierarquizada do comando (DEJOURS, 1992).

Desse cenário emerge a necessidade de reestruturação de tarefas como alternativa para a Organização Científica do Trabalho; esse processo faz nascer grandes discussões sobre o objetivo do trabalho, a relação homem-tarefa, e acentua a dimensão mental do trabalho industrial (DEJOURS, 1992). De tal modo isso ocorre que, somado às vozes de todos os trabalhadores recém colocados em escritórios e nas indústrias, surgem novas condições de 
trabalho que expõem os operários a novos sofrimentos. A este fato Dejours (1992) se refere como a "crise de civilização": o aparecimento de uma série de contestações da sociedade.

Esta crise traz consigo o impacto da droga e das toxicomanias que, segundo Dejours (1992), são testemunhas de uma nova procura: o prazer de viver. Os principais envolvidos nesse movimento societário, que busca a todo custo o prazer, são os filhos da burguesia e da classe operária. É nesse contexto que surgem os movimentos de libertação:

em 1968 aparece como uma data representativa na história da relação saúdetrabalho, é primeiramente em razão do desencadeamento verbal ocorrido durante os acontecimentos de maio de 68. No centro do discurso de maio de 68 encontramos a luta contra a sociedade de consumo e contra a alienação. (...) Simultaneamente, o trabalho foi reconhecido como causa principal da alienação, inclusive pelos estudantes (DEJOURS, 1992, p. 24).

As greves selvagens e as greves de operários não-qualificados eclodem espontaneamente, justificando a escolha de 1968 como referência histórica e designativa das novas tendências para incitar os conflitos sociais. A palavra de ordem doravante será "mudar de vida", muito presente nas greves, colocando o Estado e o patronato numa atonia, cuja duração se projeta até a atual crise econômica, que tende a atenuar as reivindicações qualitativas.

A origem do termo "trabalho" tem um interesse particular no presente texto. Segundo Jacques (1996), há uma associação controvertida nesse termo, relacionado ao sofrimento e à transformação da natureza através da atividade humana. No latim, tripalium é um instrumento de tortura e um instrumento agrícola de cultura de cereais.

O autor defende a estreita relação entre o trabalho e a identidade do sujeito humano, ao ressaltar que o trabalho foi extremamente exaltado na sociedade ocidental a partir da implantação e consolidação do sistema capitalista. $\mathrm{O}$ trabalho tornou-se categoria explicativa do processo de desenvolvimento filogenético da espécie e representação da condição humana. Dessa maneira, diferentes espaços de trabalho vão constituir oportunidades diversas para a aquisição de atributos que qualifiquem a identidade do trabalhador. Alguns espaços e categorias profissionais associam tal prestígio ou desprestígio social que, segundo Jacques (1996), proporcionam atributos de qualificação ou desqualificação ao sujeito. Ele cita que em alguns casos a qualificação é tão representativa que o prefixo "ex" é adotado para suprir a identidade em situações como a aposentadoria, por exemplo. Certos sujeitos podem chegar a buscar atividades com o intuito maior de adquirir reconhecimento social do que uma remuneração. Uma atividade desta, segundo ele, proporciona a experiência do sentir-se vivo, já que sua 
ausência está associada à morte, à exclusão e à segregação (JACQUES, 1996). Se por infortúnio não houver concretização desta busca, "lembranças de trabalho são evocadas como justificação de toda uma biografia e de reconhecimento social" (BOSI, 1987 apud JACQUES, 1996, p. 25).

É importante (...) compreender esse humano inscrito em um contexto socioeconômico que exalta o ato de trabalhar e lhe confere valor positivo, faculta-se a significância ímpar na existência, constituindo-se como representante do eu. Os cotidianos laborais e suas determinações qualificam o personagem trabalhador e se expressam nas respostas à pergunta "quem és”(...) (BOSI, 1987 apud JACQUES, 1996, p. 26).

Que conexões são possíveis desta temática com a questão da multiplicidade da vontade de poder arrolada aqui anteriormente? O indivíduo busca, a partir de sua "vontade", conquistar aquilo que é "considerado" melhor. As aspas visam ressaltar que aquilo que é considerado como valioso por um sujeito passa, necessariamente, pela caução do contexto. Em outras palavras, o indivíduo possui uma vontade perpassada por inúmeras vontades; tudo isso faz com que ele aja em função da conquista do poder, ou do que seja considerado poder no seu contexto.

Zanelli e Bastos (2004) incrementam a problemática do processo de trabalho sob o impacto das inovações tecnológicas, que alteram a relação dos sujeitos com a atividade do trabalho e demandam novas habilidades e competências. Estas novas exigências suscitam grande pressão imposta sobre os indivíduos para que dominem cada vez mais tipos de tarefas e desenvolvam competências múltiplas. A ameaça de desemprego e a contínua solicitação de engajamento e participação obrigam o trabalhador a incorporar, ou pelo menos a aderir, aos valores, crenças e propósitos da organização (ZANELLI e BASTOS, 2004). Toda essa pressão sobre o indivíduo resulta em grande desgaste físico e psicológico; além dessa pressão por competência no trabalho há, por outro lado, a cobrança por equilíbrio psicológico do sujeito, ou seja, o trabalhador deve, não obstante todo o sofrimento e pressão que vive no emprego, lidar bem com todas as adversidades fora do trabalho.

Considerando esta situação, Zanelli e Bastos (2004) afirmam que os prejuízos para a saúde do trabalhador atingiram proporções epidêmicas e têm suas causas, de modo geral, nas tendências econômicas e tecnológicas. Declaram: "Nas organizações que visam fins lucrativos, em grande parte, imperam valores que desprezam a qualidade de vida" (ZANELLI; BASTOS, 2004, p. 482): 
freqüentes: a falta de controle sobre o próprio trabalho, de recompensa justa, de união entre as pessoas e de equidade (ZANELLI; BASTOS, 2004, p. 482).

Todos esses índices aqui arrolados apontam para a questão da saúde do trabalhador. Será que os seres humanos são capazes de permanecer saudáveis sob condições tão despotencializadoras?

Para Nietzsche (2004), o que é bom é o que desperta o sentimento de poder, a vontade de poder e o próprio poder, no homem; a felicidade é a sensação de ampliação do poder, de um desafio vencido. O trabalhador, de modo geral, não experimenta esse saudável modo de ser. Nessa tendência alienante e despotencializadora do sujeito, o trabalho se torna um mero dispositivo que assegura uma espécie de sobrevida ao sujeito.

Teríamos então construído um sistema que esvazia os sujeitos de suas possibilidades criativas? Será que este sistema, do ponto de vista concreto, com as oportunidades de trabalho que dispõe, permite a compreensão, elaboração e implementação do significado do conceito cunhado por Nietzsche, a vontade de potência?

Dejours (1992), levantando a preocupação com a saúde mental do trabalhador, se remete à psicopatologia. Delata que o objetivo desta é "explicar o controle externo do poder sobre os trabalhadores através dos atos impostos: movimentos, gestos, ritmos, cadências e comportamentos produtivos" (p. 26). Assim, o repertório de comportamento do "operáriomassa" se relaciona com sua personalidade primeiramente pela dominação de sua vida mental manejada pela organização do trabalho, recebendo o incremento da ocultação "de seus desejos no esconderijo secreto de uma clandestinidade imposta" (DEJOURS, 1992, p. 26).

Retomemos ao problema do poder: onde habita, neste cenário? Nos remetemos às lutas operárias, às greves, à dominação dos operários, à opressão sobre estes, à doença a que são submetidos, ao lucro que de qualquer modo se garante no seu manejo, etc. Contudo, indaga-se: onde está o poder em toda essa problemática? Quem o possui? Seriam os operários vítimas desse sistema? Seria essa uma máquina de moer gente?

Foucault diria que

Onde há poder, ele se exerce. Ninguém é, propriamente falando, seu titular; e, no entanto, ele sempre se exerce em determinada direção, com uns de um lado e outros do outro; não se sabe ao certo quem o detém; mas se sabe quem não o possui. (...) Se a leitura de seus livros (do Nietzsche e a filosofia até o que pressinto ser o Anti-Édipo: Capitalismo e Esquizofrenia) foi tão essencial para mim, é que eles me parecem ir bastante longe na colocação deste problema: sob o velho tema do sentido, significado, significante, etc., a questão do poder, da desigualdade dos poderes, de suas lutas. Cada luta se desenvolve em torno 
de um foco particular de poder (um dos inúmeros pequenos focos que podem ser um pequeno chefe, um guarda H.L.M., um diretor de prisão, um juiz, um responsável sindical, um redator-chefe de um jornal). E se designar os focos, denunciá-los, falar deles publicamente é uma luta, não é porque ninguém ainda tinha tido consciência disto, mas porque falar a esse respeito - forçar a rede de informação institucional, nomear, dizer quem fez, o que fez, designar o alvo - é uma primeira inversão de poder, é um primeiro passo para outras lutas contra o poder. Se discursos como, por exemplo, os dos detentos ou dos médicos de prisões são lutas, é porque eles confiscam, ao menos por um momento, o poder de fala da prisão, atualmente monopolizado pela administração e seus compadres reformadores (FOUCAULT, 2000, p. 75, 6).

Foucault é contundente ao declarar que a posse do poder inexiste; o que existe é o movimento do poder, ele se exerce e é, momentaneamente, exercido. Diria, então, que ele, o poder, é de todos e não é de ninguém.

Um aspecto relevante deste trecho é a menção que Foucault faz a Nietzsche. Visto que nele se tenta demonstrar as similaridades no pensamento de ambos, é importante ressaltar uma passagem em que o próprio Foucault afirma a autoridade de Nietzsche na sua compreensão de mundo, e, especialmente, na questão do poder.

Parece que, ultimamente, o poder tem estado do lado de uns mais do que de outros. Mesmo que não haja ninguém que o possua, há quem freqüentemente se beneficie. Esta afirmação pauta-se na observação empírica e também nas colocações de alguns dos autores que discutiram sobre trabalho e informaram sobre a situação mais atual. Em outras palavras, o trabalhador vem sendo submetido a condições subumanas há tanto tempo que se pode duvidar de uma efetiva atuação do poder a partir deste lado do jogo. O trabalhador, em grande parte, sofre. Corroborando com esta afirmação, Jacques (1996) coloca que foi constatado, em escala mundial, que as doenças psiquiátricas e somáticas com fortes fatores emocionais (ex: hipertensão) são os grandes motivos do afastamento do trabalho, aliados à presença da morte por excesso de trabalho.

A presença dos jogos de poder nas relações de trabalho tornou-se evidente. Em qualquer que seja o movimento de luta ou de opressão, o poder sempre estará presente, de diversas formas. Segundo Foucault (2000), a realidade do poder não está centrada na política e em suas competições e distribuições de poder, mas está em "uma fábrica, uma escola, uma caserna, uma prisão, um comissariado" (p. 75). Enfim, o poder encontra-se atuando em todas as relações possíveis na sociedade humana e, sobretudo, no trabalho.

\section{Considerações finais}


Convergências conceituais entre os autores visados? Retomemos o percurso, com a diferença de que, desta vez, as noções que desejamos franjear estarão sobrepostas e suas semelhanças realçadas.

Para Foucault, o poder é algo que circula, se exerce em rede, não está sob o domínio ou controle de um eixo central. Os indivíduos, nesta perspectiva, são centros de transmissão de poder; que os atravessa.

Com a vontade de poder pudemos nos referir a uma realidade que se manifesta de modo múltiplo. Mais especificamente, uma realidade que é constituída de um "jogo complexo" de forças agindo e reagindo incessantemente em luta recíproca (LEFRANC, 2005), enfim, como o próprio Nietzsche afirma, "o mundo é da vontade de poder e nada mais" (NIETZSCHE apud LEFRANC, 2005, p. 127).

Lefranc (2005, p. 112) levanta uma questão pertinente a esta discussão: “Deveríamos chegar ao ponto de dizer que, na expressão vontade de poder de Nietzsche, o poder é tanto querendo como querido?". Este questionamento ilumina um paralelo entre a afirmação realizada aqui, que pretendia que o poder em Foucault é de todos e não é de ninguém, com o querer inerente à vontade de poder: onde estará o possuidor da vontade, do poder? Na expressão vontade de poder não se pode, segundo Lefranc (2005), tomar a vontade como causa e nem o poder como fim. Sendo assim, dificilmente a questão anterior será respondida diretamente como se espera; tanto a vontade quanto o poder estão circulando em uma rede de relações, eles não são de nada nem de ninguém, eles podem estar de um lado ou de outro em determinado momento, ao que tudo indica, Nietzsche e Foucault concordam com esse ponto.

Nietzsche afirma que em todo e qualquer ser vivo existe a vontade de poder. Entretanto, essa vontade de poder não se limita apenas aos organismos vivos, ela é mais ampla do que os impulsos orgânicos de sua sustentação. Há uma interferência da vontade de poder na vida, seja por meios inorgânicos, seja através dos desejos e de relações que os homens entabulam entre si, seja em função do dinheiro, do clima, da geografia etc. A vida, então, é um processo contínuo em transformação, já que está sujeita à atuação incessante de forças variadas, da vontade de potência, do poder. Todo esse movimento é competente na construção de individualidades, perspectivas, vontades de verdade, valores.

Esta vontade de poder é base de todas e quaisquer outras vontades. A vontade de verdade é um exemplo da manifestação da vontade de poder. Assim como em sua história o homem alcançou o desenvolvimento de técnicas, das tecnociências e o domínio dos próprios instintos 
e desejos, a vontade de verdade desses homens os leva a uma busca para conceber, em pensamento, todo o mundo à sua volta. Considerando que esta vontade é derivada de uma vontade de potência, pode ser afirmado que cada sujeito terá sua maneira singular de conceber os fatos e as ideias. De forma que a verdade absoluta inexiste, visto que foi concluído que a vontade de potência, sendo um constante conflito de forças, está em incessante transformação, assim como os indivíduos e perspectivas inerentes às relações.

Possivelmente estas colocações podem trazer consigo a confirmação da assertiva de Lebrun (1999), ao dizer que o poder é um produtor e organizador de forças, visto que nestas relações de forças há sempre a imanência de condutas e eventos únicos produzidos por estas mesmas relações. Foucault (2000) fundamenta esta concepção ao colocar que o poder é muito menos repressivo do que produtivo. Para ele, dessa função de produção surgem realidades, sujeições, objetos, opiniões, discursos e comportamentos.

Enfim, puderam ser observadas semelhanças no âmbito "produtivo" do poder: pouco controlador, mas incitador de condutas e vontades, opiniões e desejos. Tanto Nietzsche quanto Foucault abordam, de certa forma, o poder como um grande sistema de forças em intensas relações, das quais se originam todos os eventos sociais ou privados.

A revisão bibliográfica presente neste trabalho é restrita e, conseqüentemente, não permite generalizações sobre a presença de Nietzsche em todo o discurso de Foucault. Entretanto, tornou-se ao menos evidente, através das várias colocações do próprio Foucault e de seus comentadores, que o filósofo alemão do século XIX é fonte de inspiração do psicólogo e filósofo francês do século XX na composição de seu saber.

\section{Referências}

DALlABRIDA, E. Foucault e a História: Discurso, Poder e Influência de Nietzsche. Departamento de Filosofia UNICENTRO - Guarapuava/PR, 2002.

DEJOURS, C. A loucura do trabalho: estudo de psicopatologia do trabalho. São Paulo: Cortez Oboré, 1992.

DREYFUS, H. L.; RABINOW, P. Michel Foucault: uma trajetória filosófica: para além do estruturalismo e da hermenêutica. Rio de Janeiro: Forense Universitária, 1995.

FOUCAUlt, M. Arqueologia das Ciências e História dos Sistemas de Pensamento. Coleção Ditos \& Escritos (org). Manoel Barros da Motta, vol. II. Rio de Janeiro: Forense Universitária, 2000.

1999.

História da Sexualidade vol. 1: Vontade de Saber. Rio de Janeiro: Edições Graal, 
Microfísica do Poder. Ed. 15. Rio de Janeiro: Graal, 2000.

Vigiar e Punir: História da Violência nas Prisões. Petropólis: Vozes, 1999.

GIDDENS, A. A Transformação da Intimidade: sexualidade, amor \& erotismo nas sociedades modernas. São Paulo: Editora da Universidade Estadual Paulista, 1993.

JACQUES, M. G. C. Identidade e Trabalho: uma articulação indispensável. In: TAMAYO, A. et al (org.), Trabalho, Organizações e Cultura. São Paulo: Estação das Artes Produções Gráficas, outubro/1996. Volume 1, número 11, capítulo I, p. 21-26.

JÚNIOR, O. G. Labirintos da Alma: Nietzsche e auto-supressão da moral. ed. 2. São Paulo: UNICAMP, 1996.

LEBRUN, G. O Que é Poder. São Paulo: Brasiliense, 1999.

LEFRANC, J. Compreender Nietzsche. Petrópolis, RJ: Vozes, 2005.

MACHADO, R. Zaratustra: Tragédia Nietzschiana. ed. 3. Rio de Janeiro: Jorge Zahar, 2001.

MORAES, T. D.; NASCIMENTO, M. L. do. Da norma ao risco: Transformações na produção de subjetividades contemporâneas in: Psicol. Estud. Vol. 7 no. 1 Maringá, Jan./Jun. 2002.

NIETZSCHE, F. W. O Anticristo. São Paulo: Martin Claret, 2004.

Assim Falava Zaratustra. São Paulo: Escala, 2005.

Para Além do Bem e do Mal. São Paulo: Martin Claret, 2004.

STRATHERN, P. Foucault em 90 minutos. Rio de Janeiro: Jorge Zahar, 2003.

Nietzsche em 90 minutos. Rio de Janeiro: Jorge Zahar, 1997.

ZANELli, J. C.; BORGES-ANDRADE, J. E.; BASTOS, A. V. B. Psicologia, Organizações e Trabalho no Brasil. Porto Alegre: Artmed, 2004. 